\title{
Anaesthesia for Cesarean Section in a Tertiary Care Center
}

\author{
CK Shrestha ${ }^{1}$ \\ 'Department of Anaesthesiology, Paropakar Maternity and Women's Hospital, Thapathali, Kathmandu, Nepal
}

\begin{abstract}
Background: Cesarean section is in rising trend both in developed and developing countries. The role of appropriate choice of safest anaesthetic technique for individual patients depends upon number of factors. The study aims to find the pattern of anaesthesia used in tertiary care setting.

Methods: A retrospective study using secondary data from the hospital was analyzed among total of 2044 cases from April 2005 to April 2006. Demographic profile and use of different types of anaesthetic technique were studied. Descriptive analysis was used to calculate the frequency and percentage and their relations.

Results: Most patients fell on the age groups, 848 (41.48\%) in 21-25 followed by $602(25.08 \%)$ in 26-30 and 321 $(15.65 \%)$ in 14-20. Out of the total 2044 cases, 1983 (97.01\%).were emergency cesarean and 61 (2.98\%) were elective cesarean. The top three indications for cesarean section were previous cesarean section, fetal distress and cephalopelvic disproportion. Previous cesarean section was found to be in 520 (25.4\%), and Fetal distress in 434 (21.5\%), and cephalopelvic disproportion in 207 (10.6\%). The choice of anaesthesia among this group showed spinal $1632(79.84 \%)$ being the preferred choice followed by general anaesthesia $402(19.66 \%)$ and local epidural anaesthesia $10(0.48 \%)$.

Conclusions: Majority of the cesarean section are emergency. The preferred choice of anaesthesia is spinal. Previous cesarean section is the commonest indication followed by fetal distress and cephalopelvic disproportion.

Key words: cesarean section, general anaesthesia, previous cesarean section, spinal anesthesia
\end{abstract}

\section{INTRODUCTION}

Cesarean section has become more common especially in large hospitals with high risk pregnancy. ${ }^{1}$ From the anaesthesia prospective, the incidence of complications is decreasing due to better techniques and monitoring - this has occurred even with the tremendous increase in the number of these surgeries. The choice of what anesthetic technique is safest and most appropriate for an individual patient depends on a number of factors.
Ultimately the choice of anesthesia should be made once the anesthesiologist looks at all the data available and discusses the risks and benefits of each choice with the patient. Basically there are two general categories of anesthesia for cesarean section - general anesthesia and regional anesthesia. ${ }^{2}$ General anesthesia, however, is becoming less popular for obstetric anesthesia, and thus fewer cesarean sections are conducted using this technique ..$^{2,3}$ 
The objective of our study is to look at the pattern of anaesthesia undertaken at maternity hospital and their demographic variation. In addition, the study aims to find the the common indications, pattern of emergency and elective cesarean section done at tertiary care setting.

\section{METHODS}

This is a retrospective study was conducted at Maternity Hospital Thapathali, Kathmandu from April 2005 to April 2006.

Ethical approval was taken. All the data taken were collected from hospital record that underwent elective and emergency cesarean section. The data were analyzed for demographic profile of the patient, preoperative and emergency indication for surgery, and preferred type of anaesthesia. The data entry and statistical analysis were done using the Microsoft excel 2007.

\section{RESULTS}

Total number of cases included in the study was 2044 who had undergone emergency and elective cesarean section. The minimum age was 14 and maximum was 45 . In decreasing frequency, patients fell on the following age groups $848(41.48 \%)$ in 21-25 followed by 602 (25.08\%) in $26-30$ and $321(15.65 \%)$ in 14-20 (Table 1).

\begin{tabular}{|lc|}
\hline \multicolumn{2}{|l|}{ Table 1. Age wise distribution of anesthesia } \\
\hline Age & Frequency (\%) \\
\hline $14-20$ & $321(15.65)$ \\
$21-25$ & $848(41.48)$ \\
$26-30$ & $602(25.08)$ \\
\hline $31-35$ & $201(9.83)$ \\
\hline $36-40$ & $60(2.5)$ \\
$41-45$ & $12(0.5)$ \\
\hline Total & $2044(100)$ \\
\hline \hline
\end{tabular}

Among the cases total of 1983 (97.01\%) were emergency cesarean and 61 (2.98\%) were elective cesarean section (Table 2).

\begin{tabular}{|lc|}
\hline \multicolumn{2}{|l|}{ Table 2. Pavercn of Anaesthesia. } \\
\hline Frequency (Percentage) \\
\hline Emergency & $1983(97.01)$ \\
Routine & $61(2.98)$ \\
& $2044(100)$ \\
\hline
\end{tabular}

The top three indications for cesarean section were previous cesarean section (PCS), fetal distress (FD) and cephalopelvic disproportion (CPD). Previous cesarean was found to be in 520 (25.4\%), and Fetal distress (FD) in $434(21.5 \%)$, and cephalopelvic disproportion in 207 (10.6\%). Others in the table include polyhydramnoius, impending rupture, myomectomy, triplet pregnancy uncontrolled Blood Pressure, vaginal septa, primary subfertility (Table 3 ).

\begin{tabular}{|lc|}
\hline \multicolumn{2}{l}{ Table 3. Indication for Cesarean Section } \\
\hline & Frequency $(\%)$ \\
\hline APH & $71(3.5)$ \\
Big baby & $22(1.1)$ \\
BOH & $22(1.1)$ \\
Breech & $117(5.7)$ \\
Cord prolapse & $13(0.6)$ \\
CPD & $217(10.6)$ \\
Eclampsia & $14(0.7)$ \\
Elective & $10(0.5)$ \\
Failed induction & $22(1.1)$ \\
Failed vaccum & $9(0.4)$ \\
FD & $439(21.5)$ \\
Footling breech & $37(1.8)$ \\
Hand prolapse & $16(0.8)$ \\
IUGR & $8(0.4)$ \\
Leaking Per vaginum & $34(1.6)$ \\
LPOL & $7(0.3)$ \\
MS & $13(0.8)$ \\
NPOL & $13(100)$ \\
\hline Obstructed Labour & $134(6.6)$ \\
Oligohydraminous & $13(0.6)$ \\
Other & $13(0.6)$ \\
PCS & $80(3.9)$ \\
PET & $520(25.4)$ \\
PIH & $80(3.9)$ \\
Placenta Previa & $33(1.6)$ \\
PROM & $9.4)$ \\
Transverse lie & $17(0.8)$ \\
\hline Twin & $13(0.6)$ \\
\hline Tetal & $13)$ \\
\hline
\end{tabular}

$\mathrm{APH}=$ Antepartum hemorrhage, $\mathrm{FD}=$ fetal distress, $P C S=$ previous cesarean section, IUGR= intrauterine growth retardation, $\mathrm{LPOL}=$ low progress of labor, $\mathrm{PROM}=$ premature rupture of membrane, $\mathrm{PIH}=$ pregnancy induced hypertension, PET= Preeclamsic toxemia, LPV: leaking per vaginum MS: meconium stained. 
The choice of anaesthesia among this group showed spinal 1632 (79.84\%) being the preferred choice followed by general anaesthesia $402(19.66 \%)$ and lumbar epidural anaesthesia $10(0.48 \%)$ (Table 4$)$.

\section{Table 4. Type of Anaesthesia}

\begin{tabular}{|ll|}
\hline Anaesthesia & Frequency (\%) \\
\hline Spinal & $1632(79.84)$ \\
General anaesthesia & $402(19.66)$ \\
Lumbar epidural Aanesthesia & $10(0.48)$ \\
Total & $2044(100)$ \\
\hline \hline
\end{tabular}

\section{DISCUSSIONS}

To analyze the pattern of anaesthesia, total of 2044 study population who had undergone emergency and elective cesarean section were taken using hospital data. A descriptive analysis was done using secondary data collected from the hospital.

The preferred choice of anaesthesia being spinal in our context has also been consistent with the study done in other developing countries. ${ }^{4}$ In United States, regional anesthesia was used for $78-85 \%$ (depending on strata) of patients undergoing cesarean section, resulting in a marked decrease in the use of general anesthesia. ${ }^{7}$

A prospective study done in Jordan suggests that spinal anesthesia is as effective as a general anesthesia. Maternal and fetal outcome are favorable. Maternal hypotension can be managed successfully with modest doses of ephedrine and IV fluid infusions. It provides sufficient postoperative analgesia allowing the mother to have more vitality and comfort than those who receive general anesthesia. ${ }^{9}$

Majority of the cases were within the 21-25 years age group followed by 25-30 years. This suggests that cesarean rate is more common in early reproductive age groups. This is consistent with the studies done at other developing countries. ${ }^{4}$

It is surprising to see the rate of emergency section performed is very high $1983(97.01 \%)$ as compared to study done on other countries. ${ }^{5}$ This can be attributed to the fact that majority of the elective cases are converted to emergency to maintain the service to the patients. The likelihood of data entries flaws in the hospital cannot also be ruled out.

The pattern of indication for cesarean in maternity hospital shows previous cesarean section as the number one indication followed by fetal distress and cephalopelvic disproportion which is in contrast to the studies done at other developing countries hospital where cephalopelvic disproportion and fetal distress are the commonest..$^{5,6}$ The reason for this trend may be due the location of hospital at the center of the city and access to public in the capital where they are most likely to demand the cesarean as the mode of delivery. Lack of counseling about the possible vaginal delivery after previous cesarean section cannot also be ruled out on this respect. However, the study done at Nepal medical college teaching hospital showed slow progression of labor, previous CS, fetal distress and breech presentation were the first four common indications of caesarean delivery. ${ }^{8}$

As the study design was retrospective, secondary data were taken from the case files which were not always uniform and had some limitation and sometimes incomplete. This might be the limiting factor of our study.

Although adequate data were taken, study period was only one year which fails to indicate the rising or falling trend of the cesarean in our community. As the study was done in maternity hospital at the heart of the city, the coverage area and the study population fails to generalize the finding at the national level and therefore to compare with the data available regionally and with other developing nations.

\section{CONCLUSIONS}

Majority of the cesarean section are emergency with the preferred choice of anaesthesia as spinal. Previous cesarean section is the commonest indication in our hospital followed by fetal distress and cephalopelvic disproportion.

Based on our finding, a more detailed study should be conducted at national level to find the real picture of the cesarean delivery done at all levels of health care. At the same time, the role of patients awareness regarding possible discouragement of cesarean section when vaginal delivery has a role also should not be forgotten.

\section{REFERENCES}

1. Anaesthesia for cesarean section. [Online]. [Cited Sep 22, 2009]. Available from:URL:http://www.anesthesiologyinfo.com/ articles/10032002.php

2. Nakagawa M, Kinouchi K, MiyagawaY, Iura A, ShimizuT, Kitamura S. 7-year survey of anesthesia for cesarean section--comparison of tetracaine and bupivacaine as intrathecal anesthetic agents]. Masui. 2007 Jan;56(1):61-8.

3. Tsen LC, Pitner R, Camann WR. General anesthesia for cesarean section at a tertiary care hospital 1990-1995: indications and implications. Int J Obstet Anesth. 1998 Jul;7(3):145-6. 
4. Okonofua FE, Makinde ON, Ayangade SO. Yearly trends in caesarean section and cesarean mortality at Ile-Ife, Nigeria. Trop J Obstet Gynaecol. 1988;1(1):31-5.

5. Onsrud L, Onsrud M. Increasing use of cesarean section, even in developing countries. Tidsskr Nor Laegeforen. 1996 Jan 10;116(1):67-71

6. Chhabra S, Shende A, Zope M, Bangal V. Caesarean sections in developing and developed countries. J Trop Med Hyg. 1992 Oct;95(5):343-5.
7. Hawkins JL, Gibbs CP, Orleans M, Martin-Salvaj G, Beaty B. Obstetric anesthesia work force survey, 1981 versus 1992. Anesthesiology. 1997 Jul;87(1):135-43.

8. Khanal R. Caesarean delivery at Nepal Medical College Teaching Hospital, Kathmandu, Nepal.Nepal Med Coll J. 2004 Jun;6(1):535.

9. Qublan HS, Merhej A, Dabbas MA, Hindawi IM. Spinal versus general anesthesia for elective cesarean delivery: a prospective comparative study. Clin Exp Obstet Gynecol. 2001;28(4):246-8. 